\title{
Los avatares de la meritocracia
}

\section{The avatars of the meritocracy}

\author{
Alan Patroni Marinovich* \\ Facultad de Ciencias de la Comunicación, Turismo y Psicología, \\ Universidad de San Martín de Porres, Perú
}

\section{Resumen}

El presente texto es una indagación teórica sobre un tema que a pesar de su antigüedad mantiene plena vigencia: la «meritocracia», definida por el Diccionario de la lengua española (Real Academia Española [RAE], 2014) como: «Sistema de gobierno en que los puestos de responsabilidad se adjudican en función de los méritos personales». El objetivo esencial de este abordaje es mostrar el surgimiento y evolución de este término, sus variaciones a lo largo de su desarrollo conceptual, su estrecha vinculación con determinadas teorías jurídicas y sus actuales repercusiones sociales y políticas. Tratándose de una indagación teórica, el método básico asumido fue la recopilación bibliográfica y documental. Entre los resultados más destacables cabe precisar que el concepto de «meritocracia» ha sido objeto a lo largo de su evolución histórica de diversos y hasta contradictorios enfoques. En lo que respecta a las principales conclusiones hay que señalar que la meritocracia puede ser utilizada para enmascarar procesos excluyentes.

Palabras clave: meritocracia, gobierno, ascenso social, oportunidades. 


\begin{abstract}
This text is a theoretical inquiry on a topic that, despite its antiquity, remains in full force: «meritocracy», defined by the Dictionary of the Spanish Language (Real Academia Española [RAE], 2014) as: «The government system in which positions of responsibility are awarded based on personal merits». The essential objective of this approach is to show the emergence and evolution of this term, its variations throughout its conceptual development, its close connection with certain legal theories and its current social and political repercussions. Being a theoretical inquiry, the basic method assumed was the bibliographic and documentary compilation. Among the most noteworthy results, it should be noted that the concept of «meritocracy» has been the object of various and even contradictory approaches throughout its historical evolution. Regarding the main conclusions, it should be noted that meritocracy can be used to mask exclusive processes.
\end{abstract}

Keywords: meritocracy, government, social advancement, opportunities.

\title{
Introducción
}

En relación con el «mérito», Puyol (2007) precisa que es un valor omnipresente en nuestra sociedad, hasta el punto de que, basado en él, se ha desarrollado un modelo social propio de selección: la meritocracia. Indica nuestro autor que ambos términos -mérito y meritocracia- se asocian con frecuencia en torno a aspiraciones igualitarias que plantean que los individuos, en sus procesos de ascenso social, sean valorados y seleccionados por su propia capacidad y no por otras condiciones éticamente irrelevantes como el origen social, racial, cultural, el sexo, el aspecto físico, la religión o la ideología. Pero, paradójicamente, como indica Puyol (2007), el mérito y la meritocracia tienen escasa relación con la igualdad. Sin embargo, hasta el presente, el mérito se mantiene como una entidad incuestionable, vinculada sustancialmente al valor de la igualdad en los procesos de edificación de los sistemas sociales democráticos; en tanto, la meritocracia se considera todavía como uno de los mecanismos más justos, equitativos, eficientes e igualitarios al momento de seleccionar al personal dirigente en los procesos por alcanzar determinados puestos y ubicaciones. 
No obstante, como lo constatan diversas experiencias sociales y políticas, el mérito se vincula más con la eficiencia que con la igualdad, a tal punto que notables especialistas en la materia indican que, si se desea fomentar una sociedad más justa e igualitaria, es recomendable subordinar el factor mérito al factor igualdad, indicando que este procedimiento sería una de las maneras de evitar que el ya inveterado mal uso del mérito agudice más aún las desigualdades existentes. Una dificultad para el estudio del mérito y de la meritocracia es la diversidad de significados asociados, polisemia que ha llevado a especialistas como Castillo et al. (2019) a plantear su análisis mediante una triple perspectiva:

1. La perspectiva normativa. Se encuentra asociada a la filosofía política, se centra en el análisis de la justicia y sus principios, como el enfoque de Rawls (1971) y el de Sandel (1998), quienes abordan el problema de lo justo y de los criterios distributivos. Aquí la meritocracia se relaciona con la justicia, considerada esta última como equidad.

2. La perspectiva descriptiva. De tendencia sociológica, su interés apunta a cómo implementar el ideal meritocrático mediante los mecanismos de movilidad social (Alon y Tienda, 2007) y los méritos educativos. En este enfoque, la educación desempeña un rol fundamental, pues legitima la meritocracia (a mayor estudio, mayor recompensa).

3. La perspectiva subjetiva. Se centra en cómo las personas perciben las diferencias sociales de su entorno y en cómo vinculan estas percepciones a los efectos de aplicar o no un sistema meritocrático. En este campo los estudios son muy escasos, debiendo rescatarse el de Duru-Bellat y Tenret (2012), focalizado en las percepciones y preferencias sobre el sistema meritocrático.

Muy brevemente puede señalarse que el concepto de mérito ha evolucionado desde una acepción original que lo consideraba una situación vinculada con el nacimiento, la pertenencia a una familia o a una casta. El mérito, en tanto que esfuerzo para lograr el ascenso y la posición, prácticamente no existía. Luego comenzó a ser entendido como el logro de una mayor participación en el ascenso y distribución de beneficios, sustentada en el talento y el esfuerzo personal, hasta los tiempos más 
recientes en que el mérito es cuestionado críticamente señalando que es fruto de procesos elitistas y excluyentes.

Por consiguiente, en el acercamiento al mérito y a la meritocracia nos acogeremos, en lo posible, a la siguiente temática: a) sus inicios en la antigüedad; b) su resurgimiento y reformulación conceptual desde mediados del siglo pasado; c) su vinculación con los nuevos enfoques jurídicos doctrinarios; d) sus actuales repercusiones sociales y políticas.

Profundizando en la escueta y ya citada definición del Diccionario de la Lengua Española (RAE, 2014), Armas (2008) conceptualiza la «meritocracia» (del latín mereo, merecer, obtener) como una propiedad característica de los procesos burocráticos y tecnocráticos de gobierno que sustentan el ascenso social en el mérito y la jerarquía, valores sociales y educativos orientados al logro de la excelencia.

\section{Contenido}

\section{Los inicios}

El uso de «meritocracia» es de reciente data; sin embargo, Platón y Aristóteles abordaron esta problemática hace ya mucho tiempo. Puede señalarse que «mérito» y algunos de sus equivalentes como «demérito» $\mathrm{o}$ «meritorio»-y, específicamente, la palabra «meritocracia»- han sido y son largamente utilizados desde tiempos remotos, en diferentes circunstancias y desde diversos enfoques doctrinarios. El concepto de «merecimiento» derivado de la noción de «mérito» guardaba una estrecha relación con las nociones de «igualdad» $\mathrm{y}$ «desigualdad» $\mathrm{y}$, por consiguiente, con el concepto de «justicia». La idea central es que, ante las situaciones de desigualdad, la justicia debe asumir la responsabilidad ética de corregir este desequilibrio, en el plano en que se presente, sea este social, económico o político.

Desde las primeras reflexiones sobre este tema efectuadas por Platón (1964) en La República, se precisa que todas las virtudes se basan en la justicia y que esta se sustenta en la idea del bien, el cual finalmente persigue la armonía del mundo. En la obra citada, Platón señalaba, como indica Olivari (2008), que la justicia es un bien moral y por tanto un bien espiritual, sujeto 
a decisión personal, al que solo puede acceder quien posea el conocimiento adecuado; es decir, el sabio, el filósofo. Mayer (1941) resume el pensamiento elitista de Platón parafraseando que el género humano no verá días mejores hasta que el grupo de los denominados «filósofos» logre autoridad política o hasta que la clase política se convierta, por alguna circunstancia providencial, en un grupo de verdaderos filósofos.

Sin embargo, Platón no adjudicaba al «gobernante filósofo» un poder omnímodo y recomendaba a los estados limitar el poder absoluto a través de la ley. Crego (2020) ubica adecuadamente los reales alcances del absolutismo platónico al señalar que el «filósofo-rey» platónico es, esencialmente, un recurso alegórico, una abstracción. Recordemos que, en un texto no muy conocido, Platón (Carta VII) recomendaba no someter ninguna ciudad a dueños absolutos, sino a las leyes. En resumen, para Platón el gobierno de la ciudad debía estar en manos de quienes exhibieran determinadas condiciones: capacidad intelectual, formación filosófica adecuada, conducta proba y noble. El sistema educativo debía ser congruente con la aspiración política planteada por él. Es decir, la educación debía ser compatible con la organización anhelada. En una comunidad así estructurada la virtud capital es la justicia y el mérito del individuo consiste en que cada persona desempeñe lo mejor posible la misión que le corresponde según su estamento social de procedencia. Platón adjudica, como señala García (2017), una virtud particular a cada estamento social: la sabiduría para los gobernantes, la fuerza para los militares, la moderación para los ciudadanos. Es en función de este mayor o menor logro de la misión asignada que se determina el «mérito».

Por su parte, Aristóteles (1988), en su Ética Nicomáquea, plantea que la justicia es, en primer lugar, lo legal (lo justo) y, en segundo lugar, implica el respeto a la igualdad, lo que implícitamente supone la restauración del desequilibrio provocado por la desigualdad. Las nociones de «merecer», «mérito», «merecimiento» aluden en última instancia al concepto de justicia, en la medida en que el mérito y el demérito enfocados como premios o castigos respectivamente, nos conducen a la justicia como instancia que posibilita su evaluación y otorgamiento final. Para Aristóteles, la importancia del «mérito» radicaba en sus innegables repercusiones en el campo de la política, entendida esta como el gobierno de la «polis». En efecto, el 
problema político esencial que preocupaba a Aristóteles, siguiendo la ruta inicialmente esbozada por Platón, era resolver quién debía encargarse del gobierno de la ciudad para que esta funcionara adecuadamente.

Aristóteles formula al respecto tres tipos posibles de gobierno: la aristocracia, la república y la monarquía. En la aristocracia deben gobernar los ciudadanos más aptos, los más virtuosos, los mejores, los más educados; en la república deben gobernar los miembros de una pluralidad seleccionada por la comunidad y, en el tercer caso, debe mandar una sola persona: el rey. Para Aristóteles, la culminación de la meritocracia es el logro de la «dignidad», que no consiste en la posesión de honores que pueden ser injustos o indebidos, sino en el reconocimiento de merecer realmente lo que se tiene. El ideal aristotélico de justicia es dar a cada uno según su mérito, otorgar reconocimientos (derechos) sobre la base de rasgos, logros $\mathrm{y}$ acciones.

Recordemos que en El Digesto de Justiniano (D'Ors, 1968-1975), posterior recopilación y formalización romana de la legislación greco-occidental, se presenta una aproximación a la noción de justicia, según la cual esta consiste en «dar a cada cual lo que se merece»; es decir, dar a cada uno lo suyo, sentencia muy similar a la moderna expresión «la gente tiene lo que se merece».

\section{La evolución reciente}

Inicialmente, la meritocracia implicó un enfoque radical que cuestionó los tradicionales sistemas aristocráticos respecto del acceso al poder. La aristocracia en el campo militar, social, sacerdotal, etc. detentaba privilegios que se heredaban de generación en generación, por medio de sistemas basados en la raza, casta o género. La aparición de la meritocracia implicó el reconocimiento del valor y méritos de individuos que no integraban dichos grupos. El enfoque meritocrático contribuyó al desmantelamiento de la jerarquía aristocrática. Luego de una lenta elaboración conceptual durante la antigüedad, la meritocracia adoleció, tanto en la Edad Media como en la Edad Moderna, de cierto estancamiento, por la preeminencia de los sistemas teocráticos predominantes en aquellas épocas, en cuyo transcurso el mérito se encontraba fuertemente asociado a la ética; es decir, 
una persona ética en la Edad Media era una persona que cultivaba virtudes como la templanza, la justicia o la generosidad. Finalmente, en los dos últimos milenios, la meritocracia reapareció postulando un sistema de ascenso basado en la selección de los más aptos y apoyado en la justicia democrática o igualitaria. La meritocracia se planteó como un sistema consistente en distribuir las labores, los puestos y los beneficios de diversa índole de acuerdo con las cualidades y calificaciones individuales, con el fin de que las personas con mejores competencias y habilidades obtuvieran los puestos de mayor relevancia.

La meritocracia se presenta actualmente como una alternativa de progreso y ascenso social supuestamente menos imperfecta que las anteriores concepciones del mérito, basadas en las castas o en el origen social, ya que -en teoría- permite que cualquier persona pueda acceder a mayores recompensas sociales a partir del ejercicio de sus propias competencias. Es decir, se comenzó a cuestionar el antiguo paradigma de la meritocracia basada en el origen social y se planteó un nuevo enfoque que la ubicaba dentro del eje central de la igualdad de oportunidades. Ya no es el hombre que por razones apriorísticas de nacimiento está destinado a gobernar, sino que quien acceda a altos cargos debe lograrlo por sus méritos.

En este contexto, a mediados del siglo pasado aparece Michael Young (1958; 1961), quien a través de su obra más conocida El triunfo de la meritocracia, una novela de corte futurista al estilo de las publicadas por George Orwell, intentó asignar al término «meritocracia» una connotación sarcástica y negativa. Young describe una sociedad estratificada, donde el éxito -es decir, el mérito- está en función del acceso a ciertas instituciones educativas de prestigio y de tener determinadas habilidades intelectuales en alto grado. En esta sociedad imaginaria, el sistema educativo selecciona a los ganadores y descarta a los perdedores. Ubicada en este peculiar contexto, la palabra «meritocracia» asumió con el tiempo una connotación distinta de la que anhelaba Young: se convirtió en sinónimo de movilidad social en un contexto de igualdad de oportunidades; o sea, un sistema abierto, sin privilegios heredados ni favoritismos.

Desde este enfoque, la «meritocracia» designaba al gobierno ejercido por las personas consideradas poseedoras de los méritos suficientes. Este proceso 
pudo resumirse en la simple e ingenua fórmula: Inteligencia + Esfuerzo $=$ Mérito. Se planteó, idealmente, que estas personas debían ser identificadas tempranamente y debían ser cuidadosamente seleccionadas con el fin de proporcionarles una intensiva y compleja educación, congruente con sus capacidades y competencias; proceso que debía ser objeto de una intensiva supervisión y evaluación.

Young (1958) era plenamente consciente de los riesgos que entrañaba esta concepción deformada, sobre todo por parte de los partidarios del neoliberalismo; y de que esta deformación podría devenir en un modo de aristocratizar, principalmente en el campo de la educación superior. Señaló preventivamente que el concepto de meritocracia enmascaraba un proceso de dominación social sustentado en un orden jerárquico y artificioso de las personas, basado en méritos intelectuales, académicos o laborales no siempre propios ni merecidos. Así ubicadas, las prácticas meritocráticas eran excluyentes o marginadoras y, por tanto, no eran compatibles con una sociedad democrática. Young afirmaba que la meritocracia, concebida de esta manera, no es otra cosa que un sistema que justifica los privilegios de los grupos dominantes al condicionar el acceso a una educación de alta calidad solo a personas integrantes de los sectores privilegiados.

Para Young, la teoría meritocrática así deformada corría también el riesgo de ser expropiada por tendencias políticas excluyentes y marginadoras, por lo que su primera preocupación fue prevenir las negativas consecuencias de un sistema social administrado exclusivamente por criterios meritocráticos. Sustentaba este punto de vista al precisar que una élite de dirigentes seleccionados rigurosamente por pruebas de inteligencia, personalidad y rendimiento académico era injusta porque se excluía en este proceso aspectos fundamentales que requerían un estudio más profundo (motivación, esfuerzo); y lo probaba señalando, basado en datos estadísticos, que el ascenso de personas de los sectores poco favorecidos era mínimo y el descenso de las clases más favorecidas casi no se producía. Asimismo, indicó que el sistema educativo no solo no promovía un ascenso social más justo, sino que favorecía y consolidaba la reproducción del statu quo; es decir, del establishment.

Young (1996) predijo el riesgo de crear un sistema educativo, tanto público como privado, exclusivo y excluyente, con notorias reminiscencias 
darwinistas. Las riesgosas implicancias sociopolíticas de esta postura son gravísimas, ya que, al clasificar y agrupar a las personas sobre la base de sus habilidades, la diferencia entre clases aumentará, con los inevitables riesgos de la estigmatización grupal o social de los no seleccionados; situación que evocaría cercanamente la segregación nazi.

En este nuevo contexto social, las clases favorecidas no cuestionarían su estatus, ya que considerarían que su «éxito» es, simplemente, la justa retribución a su capacidad y esfuerzos. Se asumiría acríticamente que los inferiores socialmente son de hecho inferiores por su naturaleza incompetente. Es decir, se estaría promocionando inconsciente o deliberadamente una sociedad distópica, en la cual se correría el riesgo de marginar en primer lugar a los poco hábiles y luego ¿a los minusválidos y discapacitados? La búsqueda sin control de la meritocracia puede llevar a excesos lindantes con el delito. Hay que recordar la reciente Operation Varsity Blues (Gutterman, 2021), en la que el FBI puso en evidencia el fraudulento ingreso de jóvenes de la clase alta norteamericana a las universidades de mayor renombre de dicho país. Su motivación esencial era lograr en primer lugar el prestigio social (no el dinero porque sus familias disponían de recursos mucho más que suficientes) y luego exhibir méritos académicos que justificaran su acceso a las grandes empresas.

Otro elemento que no se puede soslayar, según Young (1996), es que las pruebas y exámenes que determinarían el acceso a instituciones de enseñanza superior muchas veces son cuestionadas en su idoneidad, por la simple razón de que sus constructos teóricos (personalidad, inteligencia, competencias, etc.) no están claramente delimitados. Los psicólogos aún no se ponen de acuerdo sobre la naturaleza de la inteligencia ni de la personalidad, ni sobre sus componentes; por tanto, las pruebas que supuestamente los evalúan pueden ser cuestionables y/o perfeccionables.

Finalmente, existe un punto todavía no aclarado definitivamente y es qué partes de la inteligencia o de la personalidad son heredadas y qué partes son producto del medio ambiente. Además, muchas pruebas no consideran -o lo consideran en un segundo plano- un factor muy importante para el éxito: el esfuerzo. Otro punto grave señala que determinado grupo social es el que ha concentrado, gracias a un sistema educativo altamente selectivo, 
una abrumadora experiencia en pruebas de selección, frente a las cuales los alumnos procedentes de medios poco favorecidos carecen de la experiencia necesaria. Como siempre, son las clases más favorecidas las que tienen los medios de evaluación a su alcance y, lo que es más grave, bastante de su control.

Vélez (2018) describe en términos muy claros la supuesta «situación perfecta» de la condición de igualdad de oportunidades en que se sustenta el modelo tradicional «meritocrático». Este autor indica que, teóricamente, la «igualdad de acceso se traduce en la eliminación de discriminaciones injustas y, positivamente, en la estricta consideración de los méritos. Esta es la forma de igualdad de oportunidades que satisface el modelo tradicional de la meritocracia» (p. 149). Sin embargo, Vélez (2018) y otros autores coinciden en que la situación «ideal» de equidad perfecta no se refleja en la realidad cotidiana. En efecto, la «igualdad de oportunidades» es muy difícil de lograr y, más aún, se corre el riesgo de convertirse en una situación que puede servir para ocultar iniciales desigualdades y convertirlas en «igualdades» logradas por medios no lícitos.

Alternativamente se comienza a analizar la posibilidad de elaborar una «meritocracia distributiva» que funcione dentro de un marco equitativo, para lo cual algunos especialistas recurren a los postulados del eminente jurista John Rawls (1971), quien desarrolló una teoría sobre la «justicia distributiva», la cual -según él- debía orientarse hacia la equidad. En este punto, es pertinente puntualizar que esta teoría es tributaria del pensamiento contractualista (del contrato social) de Locke, Rousseau y Kant. Según ella, el individuo cumple un doble rol: como «ciudadano» participa de la autoridad soberana y como «súbdito» debe acatar las leyes del Estado, tal como señala Cañas (2008). Pero el contrato social de Rawls asume un enfoque diferente al de los filósofos mencionados, pues considera que el sentido de justicia es la capacidad moral de la persona para evaluar las cosas como justas o injustas, y sustentar esas evaluaciones (juicios) en razones, ajustando su conducta a estas y esperando que las otras personas obren de igual manera. 
Para Rawls (1971), la sociedad es una agrupación asociativa y autosuficiente de individuos que en sus relaciones sociales acatan de común acuerdo normas de comportamiento obligatorias y que se comprometen a obrar de acuerdo con ellas. Estas reglas buscan el logro del bien común de sus asociados. Estos conforman un grupo cooperativo enfocado en lograr ventajas mutuas, afrontar los inevitables conflictos que surgirán y consolidar la identidad de intereses. El conflicto aparecerá casi inevitablemente por la presencia de intereses diversos entre las personas que aspiran a los mayores beneficios posibles. La identidad asociativa debe surgir y consolidarse cuando el grupo asuma consciente y voluntariamente que la cooperación permitirá el logro de mejores niveles de vida en comparación con los que se tendrían si se trabajara individualmente.

De esta concepción de Rawls se deriva la noción de que el objeto esencial de la justicia es la regulación de la estructura básica de la sociedad; es decir, la manera en que las grandes instituciones sociales (constitución política, instituciones económicas, sociales, políticas, seguridad jurídica, derecho civil, derecho comercial, régimen de propiedad privada, derecho de familia, etc.) distribuyan y regulen equitativamente los derechos y deberes, determinando y adjudicando de manera «justa» los beneficios derivados de la cooperación social. En un contexto así definido, la teoría de Rawls (sobre la justicia social) persigue la adecuada distribución de derechos y deberes por parte de las instituciones que conforman la estructura básica de la sociedad. Es aquí donde se pueden intuir los alcances de la «justicia distributiva».

Benfeld (2012) indica que la teoría de la justicia que Rawls denomina «justice as fairness» (justicia como equidad) formula dos principios básicos: aspiración a un igual estatus de ciudadanía y la justificación de las desigualdades sociales y económicas actuales bajo la condición de la aplicación futura de la igualdad equitativa de oportunidades. Estos serían los principios últimos para regular la estructura básica social de un régimen democrático constitucional en curso. Para Rawls el problema de la justicia distributiva, siempre dentro de los márgenes de su «justice as fairness» (justicia como equidad) es saber cómo deben regularse las instituciones de 
la estructura básica para lograr mantener un sistema social de cooperación equitativo, eficiente y productivo.

En lo que concierne al mérito, hay que indicar que Rawls, en su teoría de la «justicia como equidad», asume una perspectiva radicalmente antimeritocrática ya que considera que nadie merece a priori un lugar inicial determinado en la sociedad y que, por consiguiente, los factores contingentes, secundarios o complementarios -como la procedencia, la educación o el esfuerzo- no pueden tener incidencia distributiva decisiva.

Al respecto, cabe mencionar lo expresado recientemente por Rawls (2014):

No merecemos el lugar que tenemos en la distribución de los dones naturales, como tampoco nuestra posición social en la sociedad. Igualmente, problemático es el que merezcamos el carácter superior que nos permite hacer el esfuerzo por cultivar nuestras capacidades, ya que tal carácter depende, en buena parte, de condiciones familiares y sociales afortunadas en la niñez, por las cuales nadie puede atribuirse mérito alguno. La noción de mérito no puede aplicarse aquí. (p. 106)

El punto de vista antimeritocrático de Rawls puede ser definido brillantemente, según Lizárraga (2019), asumiendo la fraterna expresión de Louis Blanc: «Dar a cada quien, según su capacidad, a cada quien según su necesidad».

Actualmente la teoría de la meritocracia ha sido objeto de numerosos cuestionamientos, incidiendo sobre todo en lo referido a su transparencia ética, por cuanto se considera que admite la presencia de ciertos mecanismos que limitan la libre competencia. Se considera que la conocida fórmula «Coeficiente Intelectual + Esfuerzo = Mérito» es un modo de validar y legitimar las diversas prerrogativas logradas por los nuevos grupos dominantes. Cociña (2013) ha resumido de modo conciso las principales objeciones a los actuales enfoques de la meritocracia; los cuales, precisa, han sido asumidos y distorsionados por el discurso neoliberal que les adjudicó connotaciones positivas y deseables. Young tuvo que ser testigo de cómo su concepto de meritocracia, elaborado originalmente con una intención 
crítica, era asumido por el discurso neoliberal que lo utilizó para justificar sus postulados elitistas y excluyentes. Cociña (2013) resume los cuestionamientos contra la meritocracia en cinco razones fundamentales:

1. En una sociedad que se organiza según el concepto meritocrático debería primar la «igualdad de oportunidades», una condición sine qua non para construir una sociedad equitativa y justa. Sin embargo, una sociedad que asigne igualdad de oportunidades a sus miembros no necesariamente es una sociedad justa. El motivo radica en que, si bien la igualdad de oportunidades es una condición necesaria, no es totalmente suficiente para construir un orden social justo. Wright (2013) plantea que la igualdad de oportunidades presenta una serie de limitaciones. Una sociedad preocupada por proveer una estricta igualdad de oportunidades a sus integrantes, sin prestar atención alguna a los niveles de desigualdad existentes, no es una sociedad plenamente justa. Una sociedad meritocrática es una sociedad que, al menos en principio, no reduce ni elimina los niveles de desigualdad o de miseria; simplemente redistribuye más uniformemente las probabilidades de ser incluido en el grupo más beneficiado. La meritocracia no reduce necesariamente los niveles de pobreza. Disponer de un sistema meritocrático no genera mayor igualdad. Durán y Kremerman (2012) señalan que la desigualdad se supera por la capacidad del Estado de redistribuir mediante impuestos y transferencias. Es decir, la meritocracia no resuelve el asunto de la desigualdad o la pobreza, esto corresponde a los altos niveles de decisión política para corregir las desigualdades sociales por medio de la acción del Estado. El esquema meritocrático olvida que una comunidad es esencialmente un espacio de solidaridad y colaboración; es decir, es mucho más que un campo de enfrentamiento competitivo en el que los seres humanos se retan encarnizadamente por el ascenso social o laboral.

2. En todos los casos, detrás de la idea de mérito existe un concepto sobre lo que se considera valioso para una comunidad. Es decir, la noción de valioso en relación con una acción supuestamente meritoria es relativa, ya que está en función de determinados factores ambientales, culturales y educativos. No debe olvidarse que la noción de meritocracia está cercanamente emparentada con la noción de justicia, la cual también es relativa. Al respecto, Sandel (2009) afirma que indagar si una sociedad 
es justa equivale a preguntar cómo esta distribuye los elementos que consideramos valiosos (ingresos, riquezas, deberes y derechos, poderes y oportunidades, cargos y honores). Una sociedad justa debe distribuir estos apreciados bienes de forma correcta; es decir, darle a cada sujeto lo que merece. El problema surge realmente cuando nos planteamos la inevitable interrogante acerca de quién merece qué, y por qué razones. Por otro lado, no debe olvidarse que el mérito es solo uno de entre muchos criterios para decidir qué persona merece qué. El mérito y sus beneficios asociados son relativos, están en función del sistema social específico y de la forma como se organizan las estructuras de poder. Por esta razón se considera que la búsqueda del mérito es una manera de adecuarse al sistema sociopolítico vigente, sin cuestionar su naturaleza intrínseca. Es decir, muchos afirman que la meritocracia no persigue la eliminación de las jerarquías sociales, sino instituir una nueva modalidad de acceder a ellas.

La meritocracia visualiza un mundo futuro en el que los avances científicos y tecnológicos en la detección de la inteligencia y del talento permitirán seleccionar a los más aptos para que puedan acceder a niveles formativos altamente calificados. En teoría ninguna barrera vinculada al mérito personal, procedencia social, nivel social y económico, antecedentes familiares, grupo racial, género o creencias religiosas o políticas debería impedir que los mejor dotados asuman los trabajos más cualificados. Lamentablemente, el resultado de la aplicación de la utopía meritocrática no es el logro de una mayor justicia social sino, por el contrario, una sociedad muy desigual en el otorgamiento de premios y beneficios asociados a los trabajos, ya que solo se conceden en función a la eficiencia en el rendimiento y productividad laboral. Una sociedad así conformada no garantiza la eliminación de los privilegios heredados, porque es muy probable que los talentosos se aseguren de que sus hijos y familiares sigan formando parte de las élites recurriendo a la manipulación genética. Por esta razón se señala que la meritocracia no es otra cosa sino una nueva forma de justificar las diferencias sociales: ya no es la casta o la procedencia social, ahora es el mérito individual (una mezcla de talento y esfuerzo) lo que legitima la desigualdad. 
3. El sistema meritocrático tiende a generar escenarios en el que los ganadores se llevan todos los premios. En textos y numerosas entrevistas, Sandel (2009) ha reiterado que: «En meritocracia, las oportunidades en realidad no son iguales para todos». Navia y Engel (2006) son aún más explícitos al manifestar que la similitud con un "partido de fútbol» en el que supuestamente gana el «mejor» es limitada porque normalmente, en el caso de la meritocracia, son los ganadores quienes definen las reglas del próximo partido. Por esta razón, después de varios ciclos, los ganadores se llevan todos los premios. Es decir, no es que la cancha esté en malas condiciones, sino que el juego ha sido arreglado para favorecer a determinado grupo. La desigualdad de oportunidades del sistema meritocrático se pone en evidencia fácticamente al constatar con mucha frecuencia que padres adinerados no solo transmiten sus beneficios económicos a sus hijos mediante la herencia, sino que -complementariamente- les otorgan inmensas ventajas educativas y culturales inscribiéndolos en centros educativos de altísimo nivel, lo que les facilita su posterior admisión en universidades privilegiadas. Por otro lado, esta condición impulsa el desarrollo de actitudes elitistas y marginadoras en los ganadores, para justificar la situación de los perdedores en esta competencia ya «desigual» de por sí. Los ganadores argumentan que esto es así porque los perdedores no se esforzaron lo suficiente (no tuvieron el debido empeño) o porque habiéndose esforzado sus capacidades no fueron suficientes (porque son tontos).

4. Una sociedad organizada meritocráticamente conlleva el riesgo de afectar la convivencia democrática. En su noción más simple, la democracia puede entenderse como la generación de decisiones comunales en las que sus participantes intervienen en similares condiciones de igualdad. En congruencia con este principio, intervienen en las decisiones tanto los talentosos como los menos talentosos, los más aptos y menos ineptos, los motivados y los indolentes. Desde este punto de vista, una democracia no puede ser, solo y exclusivamente, un «gobierno de los mejores». Siguiendo el razonamiento meritocrático se justifica que el gobierno esté a cargo de una élite burocrática camuflada como una élite tecnocrática. Esta nueva élite sería una mezcla de aristocracia tradicional con el empresariado de siempre y con expertos burócratas; sería una élite, al 
fin y al cabo, con todos los vicios y desventajas que los gobiernos elitistas implican, entre ellos la ausencia de procesos deliberativos.

5. Se considera que una sociedad meritocrática podría representar en el futuro un severo riesgo en lo que atañe a su viabilidad y funcionalidad. Es decir, inicialmente, esta sociedad otorgaría premios desiguales (más a los más talentosos y esforzados), pero el problema es cómo garantizar que los descendientes de los grupos no favorecidos puedan superar la situación a la que sus padres han sido relegados. Inversamente, cómo controlar que los padres más talentosos trasladen el capital cultural acumulado a sus hijos, cómo se impide que los padres favorecidos dejen en herencia los bienes que la sociedad les ha asignado como premio a sus méritos. Si se impide este traspaso se quitaría a los padres favorecidos los bienes que la sociedad les otorgó y que ganaron con todo derecho como premio a su esfuerzo y talento, y se anularían los efectos de los incentivos de un sistema basado en la competencia. Por otro lado, si no se impide este traspaso, terminaríamos promoviendo el mantenimiento de la desigualdad inicial. Hayes (2012) describe esta situación llamándola la «ley de hierro de la meritocracia», que señala que eventualmente la desigualdad generada por un sistema meritocrático crecerá lo suficiente como para trastocar los mecanismos de movilidad. La desigualdad de resultados hace imposible la igualdad de oportunidades.

Muy recientemente ha surgido el jurista y filósofo Michael Sandel, quien puede ser ubicado tentativamente dentro de la corriente comunitarista, un enfoque jurídico crítico del liberalismo. Sandel es profesor de derecho en la Universidad de Harvard y es conocido por criticar la teoría de la justicia de John Rawls. Uno de los últimos libros de Sandel (2020) lleva por título La tiranía de la meritocracia, donde analiza el concepto según el cual todas las personas deben disfrutar de las mismas oportunidades, procedimiento que debe garantizar que los que logren ascender a posiciones directivas deberían conseguirlo por sus propios méritos. Sandel (2020) no coincide con esta postura y señala que, si bien la meritocracia es atractiva -al tener todos los aspirantes las mismas oportunidades y, por tanto, ser merecido el triunfo de los ganadores-, no deja de ser susceptible de varios cuestionamientos: 
1. Lograr en el plano fáctico una igualdad plena de oportunidades es una aspiración utópica. Es muy difícil, si no imposible, tener un escenario donde se compita en condición de completa igualdad de oportunidades. Por tanto, alcanzar en la práctica las condiciones ideales requeridas por la meritocracia es prácticamente imposible porque las oportunidades no son siempre las mismas. Es el caso de las familias adineradas que, por el poder que detentan, pueden transmitir sus privilegios a los hijos, aparte de asignarles ventajas educativas y culturales que colocan a sus descendientes en condiciones privilegiadas para ingresar a las universidades de prestigio. Sandel revela que la inmensa mayoría de los estudiantes de este tipo de universidades -como Harvard, Princeton y Yale- pertenece a familias muy ricas. Corrobora esta información al revelar que en las universidades estadounidenses con mayor reputación la mayoría de los estudiantes pertenece al $1 \%$ de familias con mayores ingresos del país. En consecuencia, es muy difícil si no imposible conseguir las aspiraciones de la meritocracia, ya que las oportunidades no son iguales comparando las condiciones de los alumnos con más y con menos privilegios.

2. Otro problema que acarrea la meritocracia es la actitud ante el éxito. La meritocracia produce entre las personas exitosas la convicción de que este logro se debe a sus propios méritos y que, por tanto, merecen legítimamente las recompensas y beneficios recibidos. Esta situación genera, como efecto de rebote, la creencia en los ganadores de que aquellos que no lograron el acceso son los únicos responsables de su situación. Esta creencia sobre la legitimidad del éxito conlleva la división de las personas en ganadores y perdedores, originando arrogancia entre los ganadores y humillación entre los perdedores. Esta situación puede ser percibida como injuriosa, porque se sobreentiende que, si no se ingresó a la universidad y si se está mal ubicado económicamente, el responsable es el propio individuo por no contar con las capacidades necesarias.

Sandel (2020) critica el recurso a la educación superior como mecanismo de ascenso social para superar las desigualdades existentes; esto es lo que se denomina la «retórica del ascenso». Este discurso preconiza que se debe 
contar con un grado universitario para destacar y progresar en la vida, señalando que los logros dependerán de los esfuerzos y de la calidad y cantidad de lo que se aprende. Este procedimiento era, en ciertos ambientes norteamericanos, la respuesta habitual para afrontar y superar la desigualdad. Sin embargo, se trataba de un recurso al cual pocos tenían acceso dado el reducido número de personas que ostentan un grado académico en universidades de prestigio. Consideramos importante reseñar brevemente a algunos autores que precedieron a Sandel y esbozaron diferentes puntos de vista sobre la meritocracia.

Herrnstein (1973) fue uno de los especialistas pioneros en emplear el concepto de meritocracia en el análisis del sistema social. Este autor planteó una nueva interpretación de la meritocracia señalando que la inteligencia de una persona está determinada por sus genes, planteando que debe ser uno de los principales requisitos para obtener un cargo importante. Consideraba que el coeficiente intelectual tenía un alto componente hereditario, deduciendo por tanto que la meritocracia era hereditaria y que el éxito de una persona puede predecirse analizando la inteligencia de sus padres y su ubicación en la estructura social. Esta percepción de Herrnstein fue catalogada de racista por sus contemporáneos.

Posteriormente, McNamee y Miller (2004), en su obra The Meritocracy Myth (El mito de la meritocracia), plantearon un enfoque muy cercano al actualmente vigente. Estos autores analizaron la idea del «sueño americano», indicando que, a diferencia de los países europeos gobernados por aristocracias hereditarias que constituían barreras casi insalvables para el ascenso por su naturaleza exclusivista y su rigidez, en los Estados Unidos las personas podían lograr lo que se propusieran mediante su esfuerzo. Es decir, asociaban la meritocracia al sueño americano, puesto que estaban convencidos de que el éxito de los sujetos dependía de su talento y habilidades. Sin embargo, los resultados de sus investigaciones los llevaron a concluir que en los Estados Unidos el logro de la riqueza se vincula más con la herencia que con el mérito.

Hayes (2012), por su parte, señala que el objetivo de lograr el éxito basado en el mérito postulado por el «sueño americano» fue -a la largadesnaturalizado por las élites norteamericanas que imitaron las percepciones 
aristocráticas sobre la desigualdad imperantes en los países europeos. Hayes reconoce que la institucionalización de los exámenes de ingreso a universidades de los Estados Unidos fue un notorio avance para la meritocracia; sin embargo, precisa que este proceso de admisión termina, a la larga, favoreciendo a los descendientes de las élites, por la simple razón de que los postulantes pertenecientes a los grupos privilegiados siempre dispondrán de los recursos necesarios para financiar los cursos de preparación para los exámenes de ingreso.

Cabe precisar que una situación similar ocurre en los exámenes de ingreso a las universidades públicas latinoamericanas. Si bien en teoría todos pueden postular, aquellos postulantes pudientes estarán en condiciones de pagar cursos de preparación y presentarán mayores posibilidades de ingreso. Littler (2017) indica que la idea de meritocracia actualmente vigente está vinculada a la engañosa premisa de que todas las personas pueden lograr el ascenso social solo con proponérselo; es decir, que aplicando su talento y su esfuerzo pueden avanzar. Situación, por lo demás, no corroborada por la experiencia cotidiana: la concepción meritocrática apaña y encubre una estructura individualista, injusta y excluyente que conduce a los sujetos a una situación de perpetua competencia con los demás. Sandel (2020) considera que el mérito prevalente en las instituciones educativas, en algunos casos, es indistinguible del nepotismo o del amiguismo. La meritocracia -sugirió Young hace ya más de medio siglo- puede ser un eufemismo perfectamente conveniente para caracterizar una nueva forma de exclusión.

En una reciente entrevista a BBC Mundo (2021), Sandel ha señalado que no necesariamente debe abandonarse el proyecto de igualdad de oportunidades, ya que lo considera muy importante, moral y políticamente. Precisa que el error es asumir que la creación de más igualdad de oportunidades es una respuesta suficiente para corregir las enormes desigualdades de ingresos y riqueza que ha provocado la globalización neoliberal. Indica que la pandemia del COVID-19 ha evidenciado la importancia fundamental que tienen para la sociedad muchos trabajos que, sin embargo, están muy mal pagados. 


\section{Conclusiones}

El tema del mérito y la meritocracia ha sido abordado desde la antigüedad, principalmente por los filósofos griegos Platón y Aristóteles, quienes lo plantearon como un asunto esencialmente ético y vinculado estrechamente con el gobierno de las «polis».

Por su amplitud y diversidad de significados (polisemia), el término «mérito» ha sido tratado desde diferentes enfoques, entre los que destacan el enfoque normativo vinculado a la filosofía política y al análisis de la justicia y sus principios; el enfoque descriptivo asociado al tema de lo justo, la igualdad y la movilidad social, los méritos educativos; y el enfoque subjetivo preocupado por la percepción de las diferencias sociales y la aplicación del sistema meritocrático como mecanismo de atenuación.

La revisión histórico-conceptual del mérito y de la meritocracia nos permite apreciar la evolución del primero de estos términos a lo largo de la historia. Inicialmente se asociaba al nacimiento, a la pertenencia a una casta; es decir, no existía el factor de esfuerzo por el ascenso. Posteriormente, el mérito comenzó a ser visualizado como el logro del ascenso social y una mayor participación en la distribución de beneficios, gracias al talento y al esfuerzo personal, lo que implicaba aceptar que las iniciales condiciones de desigualdad podían superarse. Finalmente, en tiempos más recientes, se cuestiona críticamente al mérito porque se le considera una ficción que enmascara procesos elitistas y excluyentes.

Sin embargo, a pesar de las objeciones anteriormente indicadas, debe reconocerse que la meritocracia significó el cuestionamiento y derrumbe de muchos de los tradicionales sistemas aristocráticos respecto del acceso al poder.

Los críticos más recientes de la meritocracia, entre ellos Sandel, manifiestan que actualmente el asunto no es la antinomia «meritocracia versus aristocracia», sino la antinomia «meritocracia versus democracia». Este autor plantea que la meritocracia es, en muchos aspectos, un ideal político atractivo, si se le contrapone al privilegio heredado, al patronazgo, al nepotismo y a la corrupción. Precisa que el mérito tiene su lugar y puesto 
bien ganados porque adjudicar roles sociales importantes a los mejor calificados es algo bueno y conveniente.

Sandel manifiesta que lo negativo de la meritocracia, y que ha sido expuesto con descarnada evidencia por la globalización, es que ha profundizado la división abismal entre ganadores y perdedores, generando actitudes elitistas en aquellos que han triunfado, alimentando su creencia de que el éxito alcanzado es solo por su obra, y que quienes han quedado atrás son responsables de su fracaso. Es lo que Sandel denomina la «tiranía del mérito». Por otro lado, señala que esta «arrogancia meritocrática» no se fundamenta de manera integral ya que, en primer lugar, las oportunidades no son verdaderamente iguales en nuestras sociedades porque los ganadores inician el proceso con grandes ventajas. Incluso, afirma el autor, si se pudiera alcanzar una total igualdad de oportunidades, sería positivo, pero no suficiente para hacer una sociedad justa o buena.

A pesar de las críticas, el pensamiento de Rawls (1971) mantiene vigencia en el campo de la filosofía jurídico-política. Este autor considera «ventajas amenazadoras» a los privilegios sociales, políticos y económicos que posibilitan que determinadas personas puedan obtener beneficios más allá de lo justo. Como la desigualdad no puede fundamentar éticamente ningún principio de justicia, Rawls establece que es necesario corregir la injusticia ajustando las condiciones de la situación contractual inicial desigual; corrección que tendría que estar a cargo de la ley y de las instituciones sociales, que deberían asegurar la igualdad de acceso a todas las personas en cuestión de derechos; así como crear mecanismos de redistribución que mejoren la situación general. Finalmente propone un sistema capitalista con instituciones sociales sólidas que apliquen un sistema de justicia equitativo. 


\section{Referencias}

Alon, S. y Tienda, M. (2007). Diversity, Opportunity, and the Shifting Meritocracy in Higher Education. American Sociological Review, 72(4), 487-511.

Aristóteles. (1988). Ética Nicomáquea. Gredos.

Armas, J. E. (2008). Los falsarios de la Historia. La realidad histórica de la Meritocracia. La Razón histórica: revista hispanoamericana de historia de las ideas políticas y sociales, 4, 38-39.

BBC Mundo. (2021). Michael Sandel: En meritocracia, las oportunidades en realidad no son iguales para todos. https://gestion.pe/economia/management-empleo/michael-sandel-en-meritocracia-las-oportunidades-en-realidad-noson-iguales-para-todos-noticial

Benfeld, J. (2012). «Justice as fairness» y la idea de equilibrio reflexivo. Revista de Derecho de la Pontificia Universidad Católica de Valparaíso, 39, diciembre, 607-635.

Cañas, R. (2008). El contrato social de Rousseau: el problema de la natural enemistad entre la soberanía y el gobierno. Revista Estudios, 21, 137-148.

Castillo, J. C., Torres, A., Atria, J. y Maldonado, L. (2019). Meritocracia y desigualdad económica. Percepciones, preferencias e implicancias. Revista Internacional de Sociología, 77(1), e117. https://doi.org/10.3989/ ris.2019.77.1.17.114

Cociña, M. (2013). Cinco argumentos contra la Meritocracia. CIPER Chile.

Crego, J. (2020). Del filósofo-rey al imperio de la ley. Una evaluación de las aportaciones de Platón al «rule of law». Anuario de Filosofía del Derecho, XXXVI, 195-224.

D'Ors, Á. (compilador). (1968-1975). El Digesto de Justiniano (3 tomos). Aranzadi.

Durán, G. y Kremerman, M. (2012). Los problemas de un sistema tributario pensado para favorecer a las elites. CIPER Chile. https://ciperchile.cl/2012/01/17/los-problemas-de-un-sistema-tributario-pensado-para-favorecer-alas-elites

Duru-Bellat, M. y Tenret, E. (2012). Who's for Meritocracy? Individual and Contextual Variations in the Faith. Comparative Education Review 56(2), 223-247.

García, J. (2017). La idea de mérito en la antigüedad griega. Universitat Jaume I. Thémata. Revista de Filosofía, 55, enero-junio, 219-248.

Gutterman, A. (Directora). (2021). Operation Varsity Blues: The College Admissions Scandal [Película]. Netflix.

Hayes, C. L. (2012). Twilight of the Elites: America after Meritocracy. Crown.

Herrnstein, R. J. (1973). I. Q. in the Meritocracy. Atlantic Monthly Press.

Littler, J. (2017). Against Meritocracy: Culture, Power and Myths of Mobility. Routledge/Taylor \& Francis Group.

Lizárraga, F. A. (2019). Igualitarismo y meritocracia: de Rawls a Scanlon. Universidad Nacional del Comahue. Facultad de Humanidades. Departamento de Filosofía. Páginas de Filosofía, 20(23), 7-32.

Mayer, J. P. (1941). Trayectoria del pensamiento político. FCE México.

McNamee, S. J. y Miller, R. K. (2004). The Meritocracy Myth. Social Science.

Navia, P. y Engel, E. (2006). Que gane «el más mejor». Mérito y competencia en el Chile de hoy. Random House Mondadori.

Olivari, W. (2008). Sobre la justicia en el libro La República de Platón. Prolegómenos. Derechos y Valores, XI(21), enero-junio, 99-108.

Platón. (1964). La República. Espasa- Calpe. 
Puyol, Á. (2007). Filosofía del mérito. Contrastes. Revista Internacional de Filosofía, 12, 169-187. https:/l revistas.uma.es/index.php/contrastes/article/view/1439/1375

Rawls, J. (1971). Teoría de la justicia (Cuarta reimpresión). FCE.

Rawls, J. (2014). Teoría de la justicia (Trad. de M. D. González). FCE.

Real Academia Española [RAE]. (2014). Diccionario de la Lengua española [Dictionary of the Spanish Language] (22 ed.).

Sandel, M. J. (1998). Liberalism and the Limits of Justice. Cambridge University Press.

Sandel, M. J. (2009). Justice. Ferrar, Straus and Giroux.

Sandel, M. J. (2011). Justicia. ¿Hacemos lo que debemos? Debate.

Sandel, M. J. (2020). La tiranía del mérito. Debate.

Vélez, F. (2018). ¿Meritocracia? ¿Para quiénes? Isonomía, 48, abril, 147-167. http://www.scielo.org.mx/pdf/is/ n48/1405-0218-is-48-00147.pdf

Wright, E. O. (2013). Transforming Capitalism through Real Utopias. American Sociological Review, 78(1), 1-25.

Young, M. (1958). The rise of the meritocracy, 1870-2033: An essay on education and equality. Thames and Hudson.

Young, M. (1961). El triunfo de la meritocracia, 1870-2033: ensayo sobre educación e igualdad. Tecnos.

Young, M. (1996). The Rise of Meritocracy. Transaction Publishers. 